\title{
CHALLENGES OF BUSINESS MODEL DIGITALIZATION IN CASE OF TRAVEL AGENCIES
}

\author{
Sanja Marinkovićc ${ }^{1}$ (i)
}

DOI: https://doi.org/10.31410/tmt.2019.307

\begin{abstract}
This paper presents a new collaborative business model developed for the needs of tourist sector in Serbia. Development of a new digital platform for travel agencies was a joint project involving IT experts and software engineers, and travel and tourism experts from several agencies in Serbia. The aim of the paper was to identify the results and benefits that the new business model could bring, as well as the challenges in implementation. Case study approach was used in order to collect relevant information from practice, to identify potential benefits and challenges for creators and first users of digital platform. In second phase of the research, the goal was to get feedback from travel agencies staff that was using a new digital platform. Through defined questionnaire they were asked to express their attitude about relevant determinants. In the conclusion, the findings from two research phases were compared and analyzed together and significant conclusions were drawn.
\end{abstract}

Keywords: Digitalization, Services, Cofer, PlusPlusNT.

\section{INTRODUCTION}

$\mathrm{T}$ he importance of introducing information and communication technologies has long been recognized in the practice of tourism services, as well as in scientific and professional work in this field. There are over 2.3 million SMEs in tourism in Europe employing around 12 million people (Dredge, et. al, 2018). Obviously, the Internet and innovative technologies have enabled important changes, new approaches to the creation and provision of services, as well as to the financing in tourism (Goertz, 2014; Barnett \& Standing, 2001; Ogonowska \& Torre, 2014; Bigné \& Decrop A, 2019). In a dynamic environment, time is an irrevocable resource. A common trend, especially among the younger generation, is the desire to book travel quickly and efficiently (Law, Leung \& Wong, 2004; Sun, et al., 2017). New concepts, such as smart tourism and smart destinations refer to the use of information and communication technologies in the development of innovative tourism services. However, these challenges, changes and trends have long been unrecognized by travel agencies in Serbia. The development of platforms to support tourism services has largely lagged behind what has been happening in developed countries over the last decade and what technological development was enabling.

The aim of this paper is to analyze a new collaborative business model developed for the needs of tourist services in Serbia. At the heart of the model is an innovative portal called Cofer that is based on an aggregate offering (https://cofer.travel). It was developed through a joint project involving IT experts from software company PlusPlusNT and travel and tourism experts from several travel agencies in Serbia. The portal automatically pulls data from CMS (content management system) and the business system of all agencies, processes the data to make the search efficient and provides an overview of the entire offer with the possibility of comparison and online booking. Despite its many benefits, the portal is not well received by end users. In order to analyze the important factors in implementation and identify the factors that are important

University of Belgrade, Faculty of Organizational Sciences, Jove Ilica 154, Belgrade, Serbia 
for success, that is, the reasons for the failure, an analysis was made among experts in travel agencies that have implemented the portal in their business.

The case study, used as a research method in the first part of the paper, was focused on different aspects of a new platform. Interviews were conducted with the most important participants in the project, with IT experts and professionals from the tourism sector. The aim of the paper was to identify the results and benefits that the new business model and platform can bring, as well as the challenges in implementation. Potential benefits and challenges have been analyzed from two perspectives: the first is related to the travel agencies' business, namely their internal and mutual business (Business to Business model, B2B) and the second is the traveller perspective (Business to Customer business model, B2C). As there were different experiences when implementing the digital business model in travel agencies, where some agencies were very proactive and flexible, others were too rigid with evident resistance to change. The results shown in case of travel agencies in Serbia could be further tested and evaluated for challenges of business model digitalization in other sectors.

\section{DIGITAL BUSINESS MODELS AND E-COMMERCE}

Digitalization is changing the way people live and work in many sectors, and that is a kind of test for traditional business models. Digital transformation can be seen as reconstructing the firm around digital operating principles, integrating traditional assets to address new challenges and pursue new opportunities (Bock, et. al, 2017). It is a challenge and opportunity, but could be seen as a threat, as well (Weill \& Woerner, 2013, 2018). In case of tourism, digitization provides technology that can create new value or increase value for tourism products and services. Experience in digitization will depend on the ability of the tourism sector to share knowledge, learn and collaborate (Dredge, et al., 2018). Digitization can encourage better communication with service users and tailoring services to their requirements, then improving quality, reaching new destinations, internationalizing, creating new business models, creating value chains. As the Internet and mobile technologies offer various tools for consumers to search and purchase products and services from suppliers directly, role of traditional intermediaries in the industry is changing (Law, et. al., 2015). The importance of digitalisation in tourism is particularly emphasized, as it is a basic prerequisite for the introduction of e-commerce in this sector. When it comes to e-commerce, although marketed in Europe can be viewed as homogeneous, there are significant differences between countries regarding national characteristics, culture, economy, social and political factors affecting the business sector.

E-commerce is one of the fastest growing industries in the whole of Europe, as the Internet enables companies to access larger groups of users and expand their markets. However, the growth of e-commerce is not equally represented in all countries, even within the European Union, where national growth rates are quite different. The highest growth rates were recorded in Eastern Europe, primarily in the countries that later became EU members. The explanation for this trend is that these were economies in transition, the maturity of their markets was not at the level of Western Europe, and thus there was more room for expansion (Ecommerce News Europe, 2014). While growth rates are significantly higher in Eastern Europe (e-commerce growth rate was 30\% in Romania), the overall value of e-commerce sector profits is much lower in these countries (Ecommerce News Europe, 2014). 
According to the report on European Tourism Market, three key aspects on the future outlook are (TOURIS Mlink, 2012):

- The evolution of $\mathrm{m}$-commerce is expected to be extremely fast, with high international roaming costs being the major obstacle,

- European travellers are forecast to use a smartphone to find travel information and/or make reservations,

- An important development is the rise of travel and tourism reservations through social networks' applications such as Facebook for iPhone.

The Serbian economy is lagging behind in digital transformation in regards to the countries of the European Union. Several recommendations for Serbian digital transformation could be found, one of which is the wider absorption and diffusion of technology (Podovac\&Petrović, 2019). In modern tourism, the user is expecting more personalized experiences and customer-centered offer, which improves comfort. ICT allowed creation of two different sub-networks: one is created by individual tourism and is increasing in importance, and the second one by the organized tourism. Implementation of ICT enhanced transition from organized to individual tourism (Hajime, 2015, Petković et al., 2018).

Generally, the service innovation in modern economy requires a wide range of technological expertise that is above the expertise level of service providers. Therefore, the innovations increasingly imply connections, linkages and cooperation of several organizations in different stages of the new service development process (Marinkovic, 2012). Co-production is evolving into co-creation, especially in terms of product innovation (Matzo-Navarro, et al., 2019). Also, there are the conclusions that business model innovation is where the greatest benefits lie (Amit \& Zott, 2012). The focus today goes to business models or marketing trends, especially in developed European economies. The changes are not important only for communication with clients and customers, i.e. B2C business models, but also for interorganizational communication and transactions in travel industry.

According to Bughin et al, (2018) more B2B companies had digitized their core offerings and operations over the past three years than had B2C players. Digitizing enabled lowering the costs and improving the reach and quality of their offerings. Blockchain's digitized verification of transactions promises to revolutionize complex and paper-intensive processes, with successful applications already cropping up in smart grids and financial trading (Bughin, et al., 2018).

In general, the market is constantly evolving and new key user groups are emerging with economic power growing. Today's customers are always trying to find the best possible solutions for their wishes and needs. Poor experience with a product or service will very easily redirect them to other options. The dynamics of market segments are changing and very volatile. One factor pointing to this is that among Generation Y members, $40 \%$ of mail and $33 \%$ of female would switch completely to online shopping if possible, while only 50\% of retail and service organizations offer such shopping as an option (Patel, 2015). Mobile commerce accounts for one-third of global e-commerce, and the security of mobile payment technology is critical to further development. A strategy focused on mobile technologies and payments could lower marketing costs because the message is sent quickly through notifications, and locating devices can easily do customer segmentation. In order to fully enable e-business, Serbia needs further harmonization of e-commerce regulations with the relevant EU regulations, abolition of the obligation to keep paper documents, harmonization of foreign exchange business legislation, etc. (Pitić et al., 2018). 


\section{DIGITAL PLATFORM FOR TRAVEL AGENCIES}

A major transformational force within the tourism sector is the digital economy, which is driving a new phase of growth and development in Europe's tourism regions (TOURIS Mlink, 2012). "The potential for structural changes in the travel sector highlights the need for travel agencies to actively select between business models which can best support an effective online strategy" (Barnett \& Standing, 2001). Traditional travel agencies must reconfigure their business processes in order to stay competitive (Abrate, et al., 2019). In online travel agencies quality is of strategic importance for competitiveness (Roger-Monzo, et al., 2015). Unfortunately, many global challenges and trends, new customer demands and behaviour have long been without any consequential reaction from travel agencies in Serbia. Contribution that travel and tourism have to the Serbian GDP is still low, as Serbia was ranked 107th globally out of 185 countries in WTTC report for 2018. (Podovac\&Petrović, 2019)

The development of platforms to support tourism services has largely lagged behind what has been happening in developed countries and what technological development was enabling. The development of a new platform that was supposed to connect numerous agencies into a common system through which they share all important information started in 2011. It started with a name Tourist Club. After the initial attempts to introduce it to the market, and many feedbacks form agencies and clients, the system was further developed and changed the name to Cofer under which it is now on the Serbian market. Today, this platform offers innovative ways for agencies to work through the digital business model.

Travel agencies perform four basic functions in the tourism market: brokerage and information-advisory (as traditional or classic) and organizer of travel and propaganda (as contemporary functions) (Spasić \& Pavlovic, 2018). In the past decade, while e-reservation services have been expanding, travel agencies in Serbia have continued to rely on existing business models that were used in the pre-digital era. Travelers were expected to take the time to visit the agency, search the printed catalogues, spend some time consulting with the travel agent, and finally make their own travel decision. The majority of travel organizers in Serbia did not offer the possibility of online bookings on their websites. Most websites offered only possibility to send a query for individual arrangements. As travel organizers did not have sufficient IT support to provide information on occupancy, sales track through intermediary, current information on their website and inability to implement online billing (Petković et al., 2018).

In the business of travel agencies, it is common that they trade between themselves by taking over arrangements from one another in order to increase the offer. These kinds of jobs are governed by a contract between an agent (tour operator) and a subagent (sales broker). Until recently, these transactions in Serbia were made through phone calls or e-mail, which was slow, unreliable, and inefficient, with a high risk of double bookings. Many transactions of different type in trading between agencies are presented in Figure 1. Each agency had similar business model with direct communication with other agencies by web site, phone, fax, regular mail and web mail. These activities were in many cases time consuming and inefficient.

It is widely accepted that Serbian tourism needs to invest more in online sales channels and promotions. While domestic customers may be accustomed to place their booking through travel organizers, the rise of foreign guests seeking additional web content should encourage local travel agencies and tour operators to invest heavily in online sales and sales support platforms (Petković et al., 2018) 


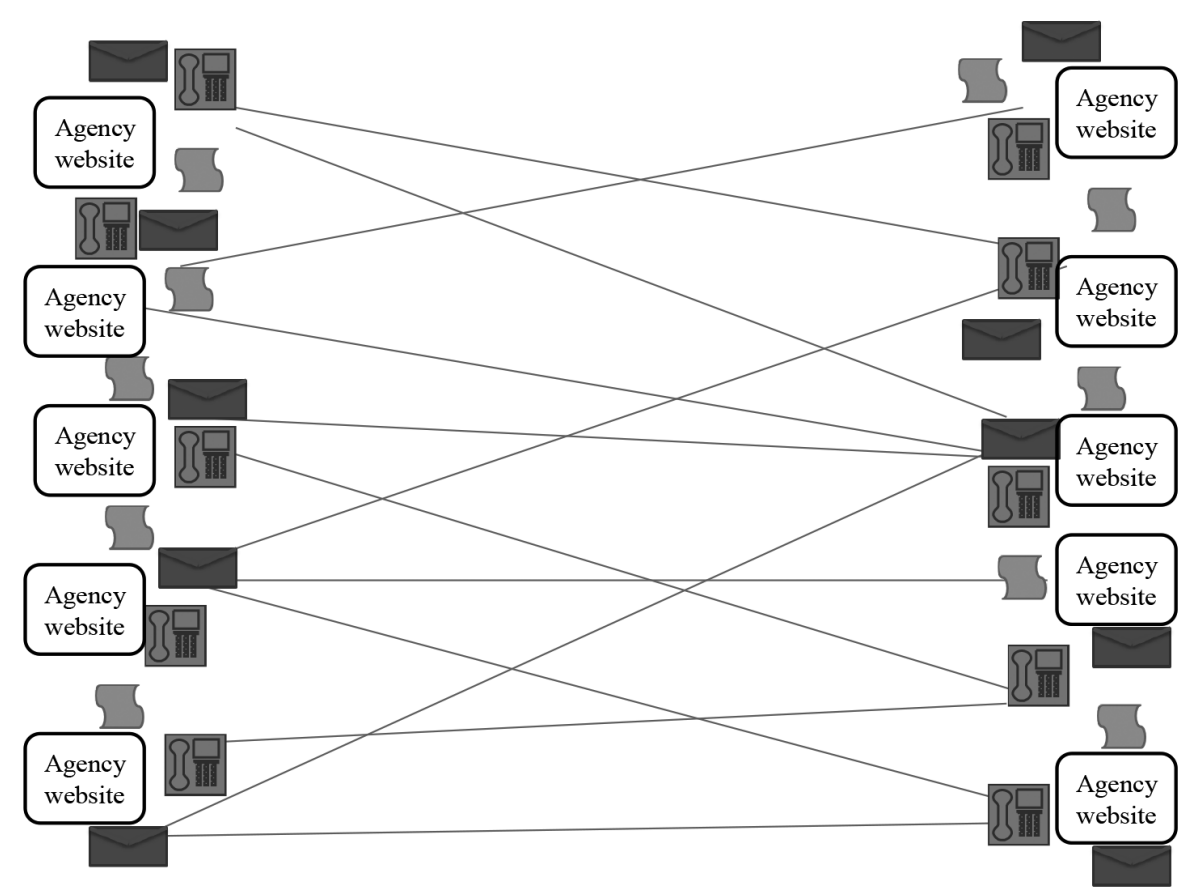

Figure 1. Transactions scheme before the changes

Source: Author, 2019

\section{CASE STUDY - COFER PLATFORM}

The Cofer platform is a complex solution for companies that organize, offer and sell tourism services in Serbia and in the region. It started under the name Tourist Club in 2010 and in 2018, it registered under a new name Cofer. Development of this platform was a collaborative process bringing together the knowledge of experts from tourism and software engineers.

The platform consists of three separate, interconnected products (Figure 2):

- Cofer Agency - Software that covers the entire value chain of tour operators;

- Cofer net - A solution that enables the automation of mutual trade in tourism products between agencies located in the system;

- Cofer portal - A platform intended for the presentation and sale of travel services by agencies located in the system.

Cofer agency is a software solution that meets the needs of the entire chain of key activities of travel agencies, from entering information about partners and their services, combining them into a tourism product and describing them, selling through different channels (branch network, website, subagent network), to preparation and monitoring the realization of services and the provision of after-sales services. Through comprehensive, real-time reporting, it provides agencies with an insight into the relationship between planned and accomplished activities in order to take the appropriate steps.

Cofer net is intended for B2B business and enables automation of trade in tourism products between authorized partners. The exchange of requests and authorization is done through the system with the possibility of printing the relevant contracts and supporting documents. Through integration with agency software, Cofer net ensures that the subagent network has insight into currently active products, without the need for additional communication. By automatically gen- 
erating the necessary documentation (contracts, invoices, etc.), it is possible to minimize the need for human labour, shorten the sales process and significantly improve the up-to-date supply.

Cofer portal is intended for $\mathrm{B} 2 \mathrm{C}$ promotion and online sale of tourism products. Clients are offered an up-to-date offer from all agencies located in Cofer system. The number of search criteria and the ability to combine them allows you to quickly find and compare products. Implemented online booking and payment rounds out the benefits associated with the online shopping process.

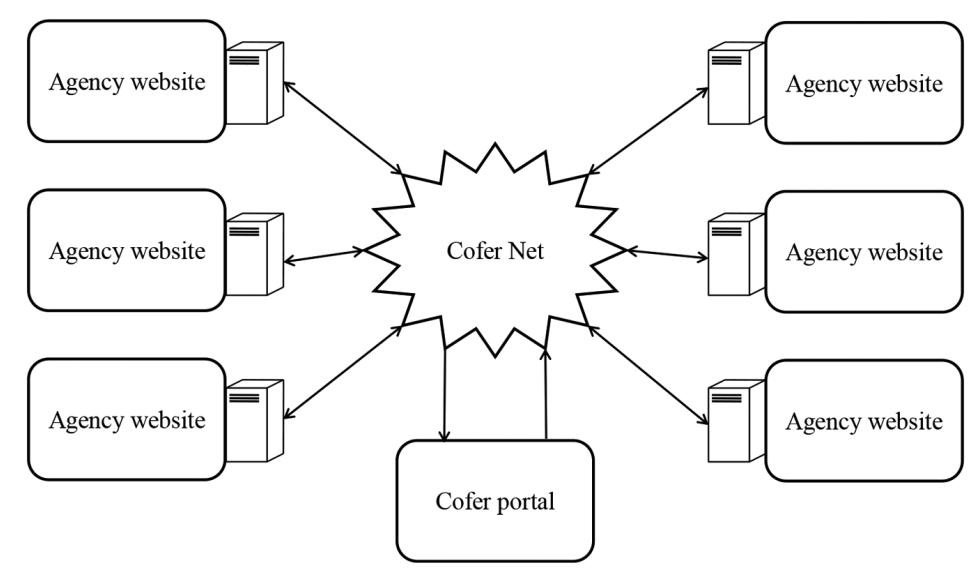

Figure 2. Transactions scheme after the changes: Logical scheme of the Cofer system

Source: Author, 2019

For Cofer tour operators, the portal is an additional channel for selling their products to end users, without the need for employee engagement, thanks to automation of request processing and document generation.

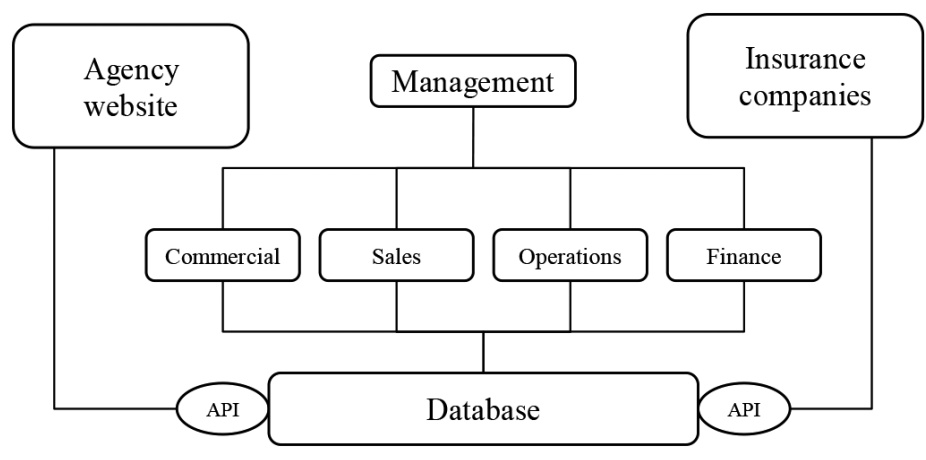

Figure 3: Logical scheme of the system in Cofer agencies

Source: Author, 2019

Figure 3 presents the logical scheme of the Cofer Agency system. Commercial operations are related to: opening of new programs, price calculation, control of rented accommodation capacities, control of leased transport capacities, definition of price lists, preparation of reports (booking lists, rooming lists etc.), then reports on occupancy capacity and realized sales volume, and automatically export data for the site. Sales activities include: creating and printing travel contracts, recording and printing payments, issuing a proforma invoice and a cashier's report. Operational monitoring tasks include: printing vouchers, printing border lists, forming visa lists, exporting insurance data and printing fiscal invoices. Financial monitoring refers to: debt review, invoicing, recording of expenses, processing of checks and reports of realized 
financial effects and the like. Management monitoring reports are usually sales reports, income statements and debt reports. From year 2011 till now, the Cofer website (www.cofer.travel) has undergone many changes in order to fulfill numerous agency requirements while enabling effective search for end users.

The research conducted in this study had two phases. In the first phase, from January 2018 till October 2019, several research methods through case study research were used in order to collect relevant information from practice. The goal was to identify benefits and challenges for creators and first users of digital platform. In second phase, travel agencies staff from agencies that were using a new digital platform and were expressing their opinions about relevant determinants. The findings were compared and significant conclusions were drawn.

\subsection{Predicted benefits and challenges for service providers - travel agencies}

The research on the digitalisation of tourism services was done through a thorough review of the original specifications of services, contracts, progress reports, UX heuristic evaluation and other materials, interviews with employees in the tourism sector and software engineers who worked directly on the new platform. The obtained answers and the results of focus group marketing testing have led to new conclusions. The recognized benefits of the new business model can be categorized into three categories: promotions related to the agency's internal operations, B2B enhancements, and enhancements to the B2C business model.

1. Internal Agency Business: The new platform provides an efficient way of creating offers, simply generates price lists and fully calculates financial obligations in almost all complicated variants that can occur in practice:

- All data on accommodation facilities and holiday arrangements are stored in a single database and are available to all employees;

- The information entered into the agency's information system (descriptions, pictures, price lists) is used to show the offer on the agency's website, which makes the process of presenting the offer completely automatic, thus significantly reducing the need for site maintenance staff;

- Booking is made possible through the agencies' websites;

- Any changes to the offer (descriptions, pictures, price lists) are transmitted almost simultaneously to the websites, and potential travellers are notified within a short period of time;

- All documentation required by law is automatically generated from the IT system;

- All documentation requested by insurance companies (travel insurance policies, etc.) is automatically generated from the IT system.

2. B2B Business Model: New software allows agencies to trade with each other directly, which means that one agency makes a reservation directly in another agency's system, with all the necessary data and calculations (it must clearly indicate that the arrangement was purchased through an intermediary). Since the process is fully automated, there is no risk of duplication of reservations.

It is possible to perform B2B integration with external partners by:

- Automatic bid import;

- Automatic updating of available capacities; 
- Automatically update accommodation descriptions and their attributes;

- Automatically forward and update the reservations;

- Automatic cancellation.

3. B2C business model: The traveller has many benefits from the new model: One can quickly find the right arrangement, in different options (for example, can search for two adults and two children, with transportation); find the best price deal comparing different offers; can decide what additional services he/she wants to buy (trips, insurance, ski pass, etc.); he/she is assured of buying arrangements and travelling on his own. At the moment there are more than 100 agencies using this platform. The most recognized on the market are: Argus Tours, Matico, Ponte, Kompas, Robinson.

The research also identified the challenges that need to be overcome in order to move to the digital business model:

- Unlike hotel bookings, price calculations for the sale of the arrangement are much more complicated as many specific cases need to be addressed;

- The capacity, accommodation and transport data must be stored in parallel;

- It is necessary to automatically generate all threatening documentation, including contracts / legal documentation as well as operational documentation;

- It is necessary to make it easy to search for package deals according to different parameters (type of accommodation, type of transportation);

- It is important to provide an efficient business and trading model between travel agencies.

The developed Cofer platform should respond to all these challenges and provide additional opportunities to enhance agency performance. The software practically enables the networking of all agencies in Serbia, creating a kind of tourist services stock exchange, enabling agencies to trade and sell complete arrangements online, either through an agency site, or through a site containing an aggregate supply of all agencies in the system.

However, the implementation of the new system was not done at the intended speed. Numerous focus group tests have revealed shortcomings, which have been corrected during the commercialization phase. Still, the number of end users, travellers, using the platform remained negligible. There was an increase in the number of people who used it to search for the arrangement, but reservations were not made through the platform. This can also be explained by the mistrust that is still present among the population in Serbia when it comes to ordering and paying online.

\subsection{Feedback from users in $\mathbf{U X}$ heuristic evaluation}

Cofer platform operated under the name Tourist Club from 2010 to 2018. First version of the website is presented on Figure 4. In order to get feedback from website users and to improve the site functionality, UX heuristic evaluation was conducted in 2017. The purpose of this analysis was to go through the website pages and evaluate it in terms of profession, design, UX, typography and composition. Generally, this analysis was not crucial to the overall website usability rating. However, when the analysis was combined with recording users in a controlled environment, it gave a realistic picture of the site itself. Additionally, it gave suggestions for improvements from a user experience standpoint. 


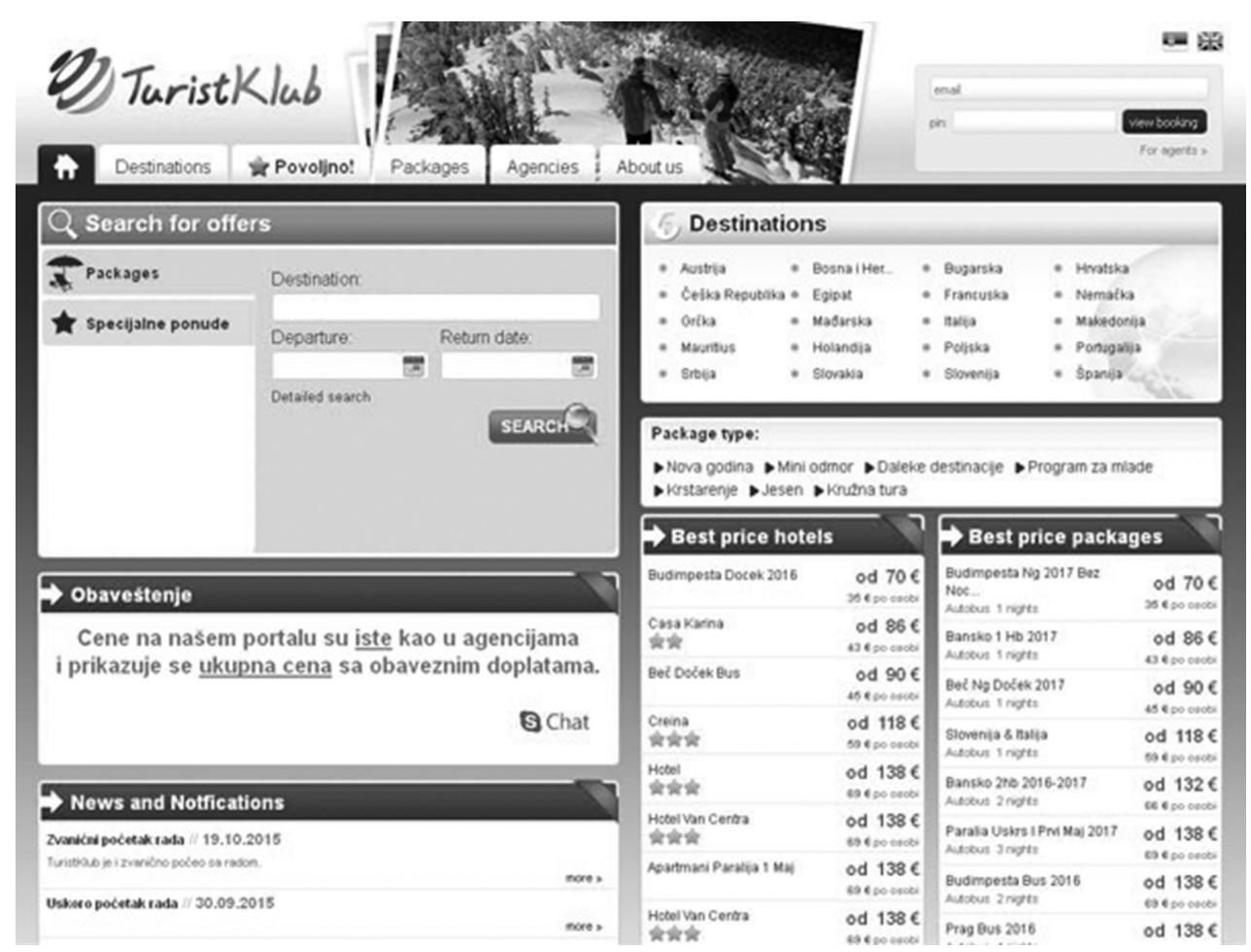

Figure 4. Tourist Club website 2017

Heuristic evaluation was based on the questions related to the following:

- Visual impression of the website: Primary purpose visible immediately, Clear design, Nice color palette, Good use of white space, Consistent design, Consistent text and colors, Responsive icons, Images have a purpose, Use of favicon.

- Content: Main titles simple and easy to understand, Website easily scans information, Minimal information immediately visible, Clear terminology, Vocabulary appropriate for all target groups, Clear information available for a specific site location, Instant information is what the user expected to find, Links are clear and consistent, Help is available on every page, Significant content is prominent and visible, Search box is easy to identify and with good readability, color selection makes it easy to read, Too much text on the site, Any unused information.

- Navigation: Consistent navigation, Easy site identification, Link to homepage displayed in many ways, Clear where to go from the current site, Limited number of links and buttons, Organization of information makes sense, Always clear what happens after the completed action, Easy to identify site location within the map, Clear where one can go beyond the current site.

- Effectiveness/Functionality: Website loads quickly, Common 404 error, Clear and purposeful error messages, Login in the top of the right corner, Contact information easy to find, Broken links, Search results intuitive and accessible, Site supports back and forward options, Easy use of contact form, Site generally behaves as expected from the website, Actions available clearly presented, Structure simple and clear without complications, Website pleasing to the eye.

- Mobile Usability Back and other relevant buttons exist, Buttons are big enough, Screen orientation works well, Consistent many, Search easy to use, Good flexibility to navigate the entire site, Design is cluttered or minimalist and clear, Loading is fast. 
In this phase, after analysis of the respondents' impressions and observations, general conclusions were:

- The information was not clear enough, it was overcrowded and the essential offers were not clearly outlined.

- The first impression of users about the site was not good, it was not the clearest at first that it was a tourist website with the arrangements of many agencies, it was not even clear enough at first glance that it is traveling website.

- Nice photos were missing.

- The search was not legible and clear enough, and for some search information was not available.

- The general conclusion was that the very structure of the information of the whole site had to be improved, as well as the visual set up of the information in order to provide a great user experience.

Based on these conclusions, the former website Tourist Club (Figure 4) was reconstructed and redesigned becoming the Cofer website that is active today (Figure 5). The website has undergone many changes in order to fulfill numerous agency requirements while enabling effective search for end users.

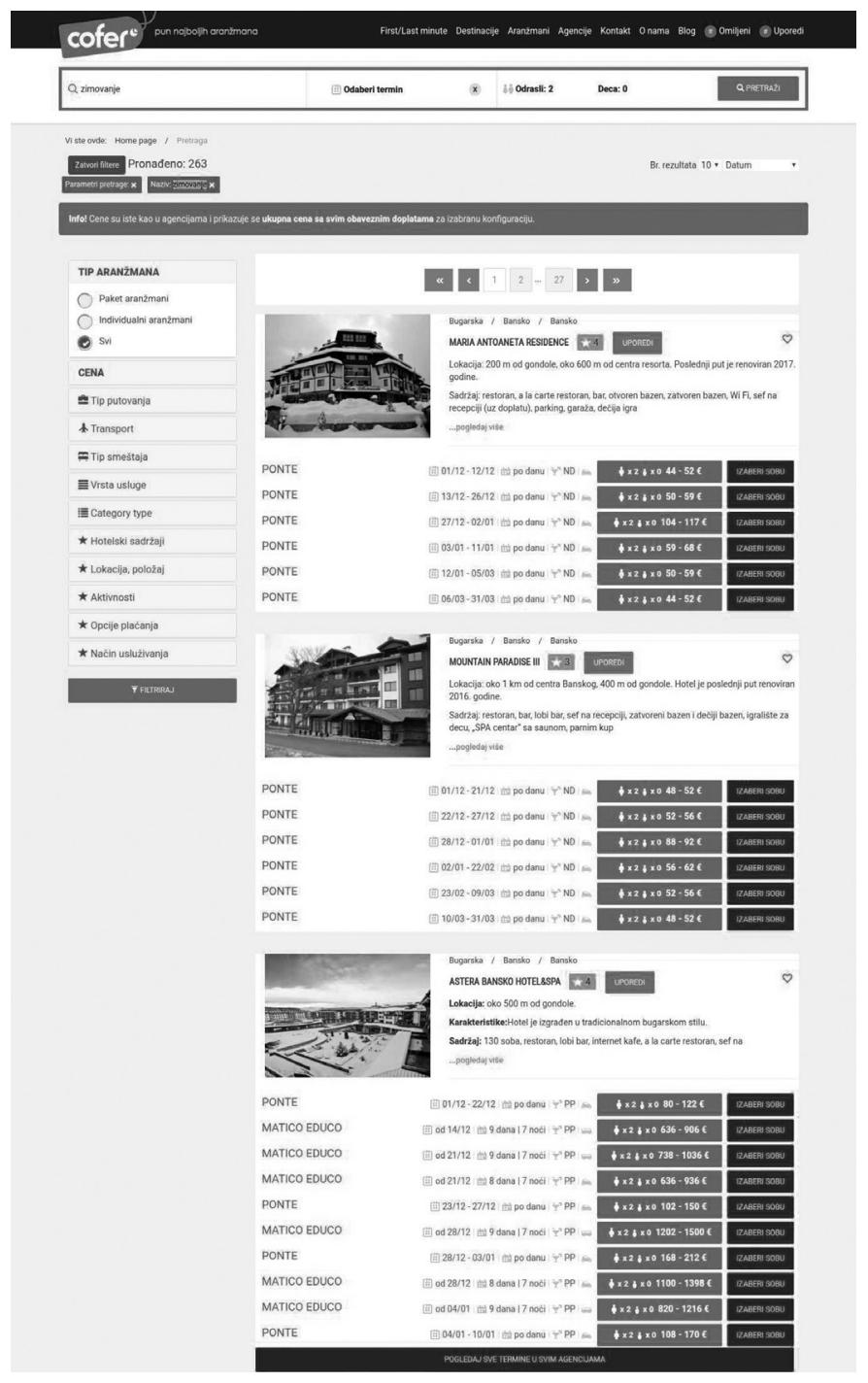

Figure 5. Cofer website 2019 


\subsection{Attitudes of travel agencies staff in implementation phase}

Research studies directed toward attitudes of employees in tourism could bring new insights, related to personal experiences and preferences related to the change that digitalization brings. Technological level reached in different environments builds a specific ecosystem that affects success of digitalisation. A survey that examined the attitudes of tourism employees in Croatia and Serbia (Slivar et al., 2016) found that employees in both countries were ready for teamwork that would provide clients with a unique experience, through new ideas and innovations. They understand the importance of training for the successful implementation of an innovation. However, while the need for employee education is expressed in Croatia, the emphasis in Serbia should be on implementing new technologies. Lack of funds and inadequate ownership structure are an obstacle to innovation in Serbia, where a large percentage of respondents thought that innovation was not a priority due to the nature of the tourist market in Serbia. Respondents (Slivar et al., 2016) believe that it is underdeveloped and therefore should not invest in innovation. These results may be one of the explanations for the rejection of the Cofer platform, both by agency employees, in introduction phase, and by end users, during the commercialization.

The introduction of the Cofer platform has brought about significant changes in the agency's business, and after initial resistance, alignment, training and implementation, it was important to examine the attitudes of employees in travel agencies regarding the digitization of their businesses.

Table 1. Determinants in digitalization of travel agencies (Dredge, et. al, 2018, adapted)

\begin{tabular}{|c|c|}
\hline & $\begin{array}{l}\text { The most significant determinants in introducing } \\
\text { digital business model in tourism }\end{array}$ \\
\hline \multirow{5}{*}{$\begin{array}{l}\text { Opportunities - expected from digital technologies } \\
\text { on operations of agencies }\end{array}$} & Customer acquisition \\
\hline & Improve online brand visibility \\
\hline & Expand international reach \\
\hline & Improve service quality \\
\hline & Increase visitor satisfaction \\
\hline \multirow{5}{*}{ Difficulties in implementing digital technologies } & Training on new digital technology \\
\hline & Cost and uncertain return on benefits \\
\hline & Insufficient knowledge to identify opportunities \\
\hline & Insufficient technical knowledge \\
\hline & Lack of suitable "off the shelf" products within budget \\
\hline \multirow{5}{*}{ Motivations why agencies seek to digitalize } & Improving online presence for competitiveness \\
\hline & Improving growth \\
\hline & Optimistic about future opportunities \\
\hline & Addressing seasonality \\
\hline & Improving networks \\
\hline \multirow{5}{*}{$\begin{array}{l}\text { Obstacles in further implementing digital } \\
\text { technologies }\end{array}$} & Lack of finance \\
\hline & Current technology level is sufficient \\
\hline & High training costs \\
\hline & Rapid pace of technological change \\
\hline & Cost of high-speed broadband \\
\hline
\end{tabular}

Therefore, the second part of the research in this paper was conducted using the questionnaire where respondents were asked to express their views on the topics relevant for successful implementation of a digital platform in tourist agencies. The factors that were presented to the respondents were grouped into four dimensions, based on research results published in Digitalization in Tourism Report (Dredge, et. al, 2018), that was a quantitative survey of 2897 SMEs, 73 public administrations, and 85 professional associations. The report analysed the challenges 
and opportunities of digitalization in tourism, defined top 5 opportunities expected from digital technologies on SME operations, top 5 difficulties in implementing digital technologies, top 5 motivations why SMEs seek to digitalize and top 5 obstacles in further implementing digital technologies. All recognised determinants are presented in Table 1.

Table 2. Evaluation of determinants by respondents from travel agencies in Serbia

\begin{tabular}{|l|c|}
\hline $\begin{array}{l}\text { The most significant determinants in introducing digital business model in tourism } \\
\text { evaluated from } \mathbf{1} \text { to 5 }\end{array}$ & Average value (tn) \\
\hline Opportunities - expected from digital technologies on operations of agencies & 4.21 \\
\hline Customer acquisition & 4.38 \\
\hline Improve online brand visibility & 3.71 \\
\hline Expand international reach & 4.17 \\
\hline Improve service quality & 4.04 \\
\hline Increase visitor satisfaction & \multicolumn{2}{|c|}{} \\
\hline Difficulties in implementing digital technologies & 3.25 \\
\hline Training on new digital technology & 3.39 \\
\hline Cost and uncertain return on benefits & 3.88 \\
\hline Insufficient knowledge to identify opportunities & 3.71 \\
\hline Insufficient technical knowledge & 3.63 \\
\hline Lack of suitable "off the shelf” products within budget & \\
\hline Motivations why agencies seek to digitalize & 4.54 \\
\hline Improving online presence for competitiveness & 4.33 \\
\hline Improving growth & 3.79 \\
\hline Optimistic about future opportunities & 3.54 \\
\hline Addressing seasonality & \\
\hline Improving networks & 4.04 \\
\hline Obstacles in further implementing digital technologies & 3.58 \\
\hline Lack of finance & 3.13 \\
\hline Current technology level is sufficient & 3.08 \\
\hline High training costs & 3.67 \\
\hline Rapid pace of technological change & 2.42 \\
\hline Cost of high-speed broadband & \\
\hline
\end{tabular}

In order to test the determinants in travel agencies in Serbia, a research was conducted, with the objective to collect the attitudes of employees from travel agencies toward the opportunities, difficulties, motivations and obstacles, after their experience with digitalization through Cofer platform implementation. The respondents were asked by sending on-line questionnaire to the official e-mail addresses, asking the respondents to rank the importance of determinants for a successful implementation of the digital model in tourist agencies in Serbia. Each response reflected a personal attitude of employee based on knowledge and experience from education and practice. Likert scale was used; an ordered scale from which respondents choose one option that best aligns with their view. This scale is often used to measure respondents' attitudes by asking the extent to which they agree or disagree with a particular question or statement. A typical scale might be "Strongly disagree, Disagree, Neutral, Agree, Strongly agree". In this case, a five-point Likert scale was used to evaluate the importance of determinant: $1=$ Unimportant; 2 = Slightly important; 3 = Important; 4 = Very important; 5 = Critical. Thirty (30) employees with minimum 5 years of experience were asked to participate in the research study, and twenty-three (23) took part in it, resulting in the participation rate of $76.67 \%$. The average importance rating, standard deviation and percentage level of importance for each evaluated determinant were obtained using statistical calculation. The questionnaire categorized main determinants related to introduction of digital business model into four dimensions based on 
Digitalization in Tourism Report (Dredge, et. al, 2018). Four dimensions of determinants for successful implementation of digitalization in tourist agencies encompassed: 1. Opportunities - expected from digital technologies on operations of agencies; 2. Difficulties in implementing digital technologies; 3. Motivations - why agencies seek to digitalize and 4. Obstacles in further implementing digital technologies.

Research results show that opportunities that are expected form digitalization from employees of travel agencies are to improve online brand visibility (4.38), customer acquisition (4.21), and improved service quality (4.17). Expanding international reach has the lowest importance in this group. When evaluating difficulties in implementing digital technologies, according to respondents, emphasis is on insufficient knowledge to identify opportunities (3.88), and insufficient technical knowledge (3.71). As motivation determinants in agencies, respondents recognized improving online presence for competitiveness (4.54) as the most important, as well as improving growth and networks $(4.33,4.04)$. At the end, the main obstacles recognized by respondents were rapid pace of technological change (3.67) and lack of finance (3.58). They do not think that considerations that sufficient technology level is very important obstacle, and the lowest importance is given to costs of high-speed broadband.

\section{CONCLUSION}

The findings and conclusions of this research add to the literature in the field of developing digital business models in tourism and set an example for practitioners working on introducing innovative platforms in services. This is of crucial importance for attracting the foreign tourists, and new generations of domestic tourists, as they are expecting more digital and more personal experience in booking. Generally, looking at published research papers and reports, some of the key challenges and difficulties observed in digital technology implementation are: digital technology training, high training costs, uncertain return on investment, insufficient knowledge to identify opportunities, lack of technical knowledge, lack of finance. However, these challenges are not present in the observed example, since the platform is very accessible to agencies, the payment for agencies is on a monthly basis, training and technical support are provided, the use of the digital platform is not demanding and can be easily accepted, both by agency staff and by end users. Despite its many advantages, implementation of digital business model is still far from expected. The causes of the slow implementation could be recognized in insufficient development of the overall market, the lack of confidence to use digital platforms and to pay online, as well as resistance to new technologies among agency staff and among users. Future research could show how these challenges are developing and overcome in practice and how the market in Serbia is changing further in the digitalization process. As stated before, the tourism sector is part of a wider system of a country and the possibilities for digitalization in services and utilization of its full potential will depend on the overall system. This is of crucial importance having in mind specific nature of services and service innovations.

\section{FUTURE RESEARCH DIRECTIONS}

This study covered different aspects of developing and implementing digital platform in travel agencies in Serbia. Limitations of the study are the small sample of respondents from travel agencies, so this result could be used as a pilot study for broader research in the future. Also, comparison of perspectives of travellers as final users and agency staff could be an object of the study. This study could give specific view on digitalization from service consumers. Managing digitalization brings 
many decision-making problems for management. Selecting the appropriate strategy is one of the most important. Further research could use the findings from this study to define decision making problem for management. With the goal of selecting appropriate strategy for digitalization of services, relevant criteria could be recognized Opportunities, Difficulties, Motivation and Obstacles, each with two or three sub criteria evaluated as the most important determinants in this study.

\section{REFERENCES}

Abrate, G., Bruno, C., Erbetta, F., \& Fraquelli, G. (2019). Which Future for Traditional Travel Agencies? A Dynamic Capabilities Approach. Journal of Travel Research.

Amit, R., \& Zott, C. (2012). Creating value through business model innovation. 2012.

Barnett M., \& Standing C. (2001). Repositioning travel agencies on the Internet, Journal of Vacation Marketing, 7(2), 143-152.

Bigné E., Decrop A. (2019). Paradoxes of Postmodern Tourists and Innovation in Tourism Marketing. In: Fayos-Solà E., Cooper C. (eds) The Future of Tourism. Springer, Cham

Bock, R., Iansiti, M., \& Lakhani, K. R. (2017). What the companies on the right side of the digital business divide have in common?, Harvard Business Review.

Bughin, J., Catlin, T., Hirt, M, Willmott, P. (2018). Why digital strategies fail?, McKinsey Quarterly.

Dredge, D., Phi, G., Mahadevan, R., Meehan, E. \& Popescu, E.S. (2018) Digitalisation in Tourism: In-depth analysis of challenges and opportunities. Low Value procedure GRO-SME17-C-091-A for Executive Agency for Small and Medium-sized Enterprises (EASME), Virtual Tourism Observatory. Aalborg University, Copenhagen.

Ecommerce News Europe. (2014). Ecommerce Serbia grows 39\% to $€ 70.4 \mathrm{mln}$ - Ecommerce News. Ecommerce News. Retrieved 10 May 2016, from http://ecommercenews.eu

Goertz, V. (2014). Travel agencies in the age of e-tourism. A comparative study of the current developments in Germany and France. Via. Tourism Review, (6).

Hajime E. (2015). New business opportunities in the growing e - tourism industry. Hershey PA: IGI Global.

Law R., Leung K., Wong J., (2004), The impact of the Internet on travel agencies, International Journal of Contemporary Hospitality Management, 16 (2), 100-107.

Law, R., Leung, R., Lo, A., Leung, D., \& Fong, L. H. N. (2015). Distribution channel in hospitality and tourism: Revisiting disintermediation from the perspectives of hotels and travel agencies. International Journal of Contemporary Hospitality Management, 27(3), 431-452.

Marinković, S. (2012). Menadžment inovacija u uslugama. Zadužbina Andrejević, Beograd.

Marzo-Navarro, M., Berne-Manero, C., Gómez-Campillo, M., \& Pedraja-Iglesias, M. (2019). Strengths of Online Travel Agencies From the Perspective of the Digital Tourist. In Predicting Trends and Building Strategies for Consumer Engagement in Retail Environments (pp. 187-210). IGI Global.

Ogonowska, M., \& Torre, D. (2014).

Patel, N. (2015) Ecommerce Techniques for Connecting with Millennial Shoppers. Kissmetrics. Retrieved from https://blog.kissmetrics.com/connecting-with-millennial-shoppers.

Petković, G., Pindžo, R., \& Agić-Molnar, M. (2018). Digital economy and (non) incremental changes in tourism and retail business model. Ekonomika preduzeća, 66(1-2), 151-165.

Pitić G., Savić N., \& Verbić, S. (2018). Digital Transformation and Serbia, Ekonomika preduzeća, 66(1-2), 107-119

Podovac, M., \& Petrović, V. S. (2019, June). Role and importance of promotion through social networks on the example of tourist organizations. In TISC-Tourism International Scientific Conference Vrnjačka Banja (Vol. 4, No. 1, pp. 536-552). 
Roger-Monzó, V., Martí-Sánchez, M., \& Guijarro-García, M. (2015). Using online consumer loyalty to gain competitive advantage in travel agencies. Journal of Business Research, 68(7), 1638-1640.

Slivar, I., Božić, S., \& Batković, A. (2016). Innovation in tourism: Perception of tourism providers from Croatia and Serbia. Review of Innovation and Competitiveness: A Journal of Economic and Social Research, 2(4), 37-56.

Sun, S., Law R., Luk, C., Fong, L.H.N. (2017). Channels for Searching Hotel and Travel Information. In: Schegg R., Stangl B. (eds) Information and Communication Technologies in Tourism. Springer, Cham

Spasić, V. Pavlovic, D. (2018). Poslovanje turističkih agencija i organizatora putovanja, Univerzitet Singidunum, Beograd.

TOURIS Mlink (2012). The European Tourism Market, its structure and the role of ICTs. Brussels: The TOURIS Mlink Consortium. Available online at: www.tourismlink.eu.

Weill, P., \& Woerner, S. (2018). What's your digital business model? Six Questions to Help You Build the Next Generation Enterprise.

Weill, P., \& Woerner, S. L. (2013). Optimizing your digital business model. MIT Sloan Management Review, 54(3), 71.

Wrigley, C., Bucolo, S., \& Straker, K. (2016). Designing new business models: blue sky thinking and testing. Journal of Business Strategy, 37(5), 22-31. 